\title{
Intercalation of Phenylalanine, Isocoumarin and Ochratoxin A (OTA) into LDH's
}

\author{
María Soledad San Román*, María Jesús Holgado \\ GIR-QUESCAT-Departamento de Química Inorgánica, Universidad de Salamanca, Salamanca, Spain \\ Email: sanroman@usal.es
}

Received 24 March 2015; accepted 11 July 2015; published 14 July 2015

Copyright (C) 2015 by authors and Scientific Research Publishing Inc.

This work is licensed under the Creative Commons Attribution International License (CC BY).

http://creativecommons.org/licenses/by/4.0/

cc) (i) Open Access

\begin{abstract}
Phenylalanine, isocoumarin and Ochratoxin A (OTA) have been intercalated within the interlayer space of layered double hydroxides. Synthesis of these nanocompounds was achieved via co-precipitation. Their physicochemical properties were studied by element chemical analysis, powder $\mathrm{X}$-ray diffraction, infrared spectroscopy and thermal analyses. The presence of OTA in the interlayer is demonstrated by the study of LC-FD Analysis. On the other hand, these studies allow to check how some of the toxin is on the surface of the nanocomposite.
\end{abstract}

Keywords

Mycotoxins, Ochratoxin A, Layered Double Hydroxide, Intercalation

\section{Introduction}

Ocratoxin A (OTA) is a mycotoxin produced by mycomicetes fungi of the genus Aspergillus and Penicillium which is widely distributed as a natural contaminant of cereals, beans and other foods and which has shown a great diversity of toxic effects in experimental studies [1]. The main contributors to OTA intake in humans are cereals and cereal products since they are the major group of food commodities where the toxin is of the greatest impact. This mycotoxin is resistant to technological processes and may persist in foodstuffs even after mould destruction [2]. Due to its physicochemical properties, OTA is easily absorbed in the gastrointestinal tract, with a bioavailability greater than $50 \%$ in all of the mammalian species tested. It shows a high affinity for the plasmatic proteins, which results in a long persistence in the organism. The main metabolites are eliminated via the renal and hepatobiliar routes, as well as through lacteal secretion. The chronic ingestion of OTA leads to the appearance of a renal toxic effect in all the monogastric mammalian species tested. Diverse studies have evidenced toxic effects of OTA on the immune system and on the nervous system. The International Agency for Research on Cancer (IARC) has classified this mycotoxin as a potential group 2B carcinogen to humans [3]. Ochratoxin A

\footnotetext{
*Corresponding author.
} 
is not produced commercially [4]; however, in 2010, it was available from 16 suppliers worldwide, including eigth U.S. suppliers [5].

The most frequently used analytical method to determine OTA is liquid chromatography (LC) coupled to fluorescence detection (FD) [6] [7].

The molecular structure consists of an isocumarin nucleus bonded to a L-phenylalanine unit by an amide bond (Figure 1).

The IUPAC name is L-phenylalanine- $N$-[(5-chloro-3,4-dihydro-8-hydroxy-3-methyl-1-oxo-1H-2-benzopyran7-yl)carbonyl]-( $R$ )-isocoumarin and its chemical abstract specification (CAS) is 303-47-9 [8]. OTA forms colorless crystals of empirical formula $\mathrm{C}_{20} \mathrm{H}_{18} \mathrm{O}_{6} \mathrm{NCl}$, which has a molecular mass of 403.822 Da [9].

Hydrotalcite-like compounds, also known as layered double hydroxides (LDHs), are a family of the so-called anionic clays. The structure of LDHs is similar to that of brucite where each $\mathrm{Mg}^{2+}$ ion is octahedrally surrounded by six $\mathrm{OH}$ ions and the different octahedras share edges to form infinite sheets. In hydrotalcite-like materials a partial substitution of divalent by trivalent cations has taken place. The chemical composition can be represented by the general formula $\left[\mathrm{M}^{\mathrm{II}}{ }_{1-\mathrm{x}} \mathrm{M}^{\mathrm{III}}{ }_{\mathrm{x}}(\mathrm{OH})_{2}\right]\left(\mathrm{A}^{\mathrm{n}-}\right)_{\mathrm{x} / \mathrm{n}} \cdot \mathrm{mH}_{2} \mathrm{O}$, where $\mathrm{M}(\mathrm{II})$ and $\mathrm{M}(\mathrm{III})$ are divalent and trivalent cations, respectively, in the octahedral positions within the hydroxide layers, $x$ is the $\mathrm{M}^{\mathrm{III}} /\left(\mathrm{M}^{\mathrm{II}}+\mathrm{M}^{\mathrm{III}}\right)$ molar ratio which value ranges between 0.2 to 0.4 [10], and $\mathrm{A}^{\mathrm{n}-}$ is an exchangeable interlayer anion [11]. The nature of $\mathrm{M}(\mathrm{II})$ and $\mathrm{M}(\mathrm{III})$ can be changed within broad ranges. These compounds exhibit a high anisotropy in their chemical bonds, which results in strong interactions within a given brucite-like layer and weak hydrogen bondings between different layers. This allows the intercalation and exchange of a wide range of organic [12]-[16] or inorganic [17] [18] anionic guests, with further influence on the properties and reactivity of the LDH material [10]. Hybrid organic-inorganic LDHs are of high interest because of their chemical, physical and mechanical properties. Applications of other types of hydrotalcite-like compounds remain in water decontamination, catalysis, photochemistry, agricultural, environmental and medicinal chemistry [19]-[22].

In this work we report results of studies of the separate intercalation of both components of OTA (namely, phenylalanine and isocumarin), as well as the intercalation of OTA in layered double hydroxides; the samples have been characterized and LC-FD has been used for detection of OTA. To the authors' knowledge, this is the first report in the literature about the interaction between OTA and LDHs.

\section{Experimental}

\subsection{Materials and Methods}

Zinc nitrate 6-hydrate (purity 98\%) and aluminum nitrate 9-hydrate (purity 98\%) were supplied by Panreac (Spain). D-L phenylalanine (purity 99\%) and isocoumarin (purity 98\%) were from Fluka (China and France). Ochratoxin A from Aspergillus ochraceus was supplied by Sigma Aldrich (Israel). Methanol (purity 99.8\%) was from Scharlau (Spain). Sodium hydroxide pellets were from Panreac (Spain). All reactants were used as received, without further purification.

\subsection{Preparation of Hydrotalcite-Intercalated by Coprecipitation}

The samples were prepared by the coprecipitation method [16] [23] using zinc nitrate $\mathrm{Zn}\left(\mathrm{NO}_{3}\right)_{2} \cdot 6 \mathrm{H}_{2} \mathrm{O}(0.05$ mol)

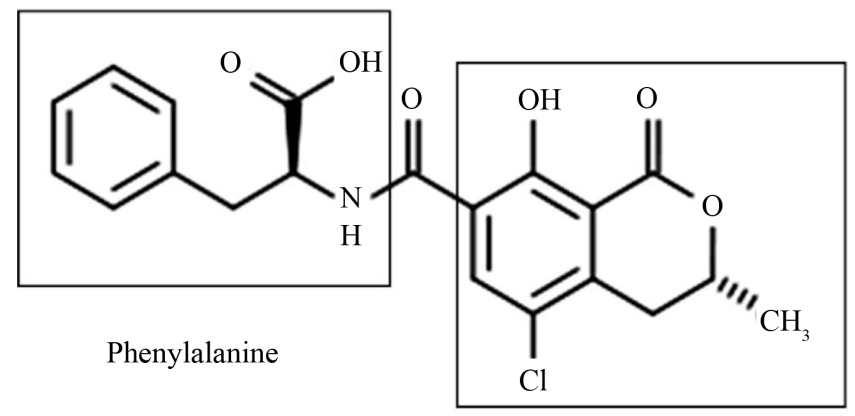

Isocoumarin

Figure 1. Structural formula of Ochratoxin A. 
and aluminum nitrate $\mathrm{Al}\left(\mathrm{NO}_{3}\right)_{3} \cdot 9 \mathrm{H}_{2} \mathrm{O}(0.025 \mathrm{~mol})$ as precursors, dissolved in $150 \mathrm{~mL}$ of decarbonated water. Other solutions $(100 \mathrm{~mL})$ were prepared using decarbonated water for phenylalanine $(0.05 \mathrm{~mol})$ and isocuomarin $(0.05 \mathrm{~mol}) .0 .00248$ mole of $\mathrm{Zn}\left(\mathrm{NO}_{3}\right)_{2} \cdot 6 \mathrm{H}_{2} \mathrm{O}$ and 0.00124 mole of $\mathrm{Al}\left(\mathrm{NO}_{3}\right)_{3} \cdot 9 \mathrm{H}_{2} \mathrm{O}$ were dissolved in $50 \mathrm{~mL}$ of decarbonated water and the solution mixed with another formed by $50 \mathrm{~mL}$ of methanol containing OTA $(0.0124 \mathrm{mmol})$ because this is insoluble in water, but is moderately soluble in organic solvents such as chloroform, ethanol, methanol, and xylene [24] [25]. Three samples with a nominal Zn:Al molar ratio of 2:1 varying the intercalated organic anions, phenylalanine, isocuomarin or OTA, were synthesized (Table 1). The solution of cations was slowly added to a basic solution of the organic anions whose $\mathrm{pH}$ was previously adjusted to 8 by addition of $\mathrm{NaOH} 1 \mathrm{M}$, maintaining the $\mathrm{pH}$ by a feedback loop $\mathrm{pH}$-meter. Once the addition was completed the suspension was vigorously stirred under nitrogen atmosphere at room temperature for $24 \mathrm{~h}$. The suspension was then centrifuged to $3000 \mathrm{rpm}$ for $5 \mathrm{~min}$ and the solid was washed several times with decarbonated water. Finally the solid was dried under vacuum at room temperature.

The sample containing OTA was prepared from the very small amount provided by the supplier $(5 \mathrm{mg})$ because of its very high toxicity. For phenylalanine and isocumarin the anion/ $\mathrm{Al}^{3+}$ molar ratio was $2: 1$, i.e., an excess was used, as the stoichiometric amount corresponds to a molar ratio of 1:1. Table 1 includes the names given to the samples prepared, the amounts of metal cations and organic component reacted and other data related to characterization of the samples.

\subsection{Sample Characterization}

Element chemical analysis was carried out in Servicio General de Análisis Químico Aplicado (Universidad de Salamanca, Spain) by atomic absorption in a Mark 2 ELL-240 apparatus after previous dissolution of the samples in nitric acid. Carbon, nitrogen and hydrogen contents were determined through a LECO CHNS-932 equipment in Centro de Microanálisis Elemental (Universidad Complutense de Madrid, Spain). Powder X-ray diffraction (PXRD) patterns were recorded on a Siemens D-500 apparatus equipped with a Daco-MP microprocessor and Diffrac-AT software, using graphite-filtered $\mathrm{CuK} \alpha$ radiation $(\lambda=1.54 \AA)$. The instrument was set at a current of $30 \mathrm{~mA}$, operating voltage of $40 \mathrm{kV}$ (power $1200 \mathrm{~W}$ ), and a scanning speed of $2^{\circ} / \mathrm{min}$ (step size $0.05^{\circ}$ and step time $1.5 \mathrm{~s}$ ) in the $2^{\circ}-70^{\circ}$ range ( $2 \theta$ scale). Identification of the crystalline phases was made by comparison with the JCPDS files [26] and literature data. The Fourier-Transform infrared spectra (FT-IR) of the samples were recorded on a Perkin-Elmer 1600 spectrometer, in the 4000 to $400 \mathrm{~cm}^{-1}$ range, with a nominal resolution of $4 \mathrm{~cm}^{-1}$ and averaging 100 scans to improve the signal-to-noise ratio. The samples were pressed in $\mathrm{KBr}$ (Merck) pellets (sample/KBr mass ratio ca. 1:300). Thermal Analysis (DTA) and Thermogravimetric Analysis (TG) of the samples were carried out in air in Perkin-Elmer DTA 1700 and TGS-2 apparatuses, respectively, coupled to a Perkin-Elmer 3600 Data Station, at a heating rate of $10^{\circ} \mathrm{C} / \mathrm{min}$. LC-FD analysis of the mycotoxin was carried out in a Varian chromatographic system (Walnut Creek, CA), which consisted of a 9012Q pump, a 9100 auto injector, and a 9075 fluorescence detector. Separation of ochratoxin A was performed on a $150 \times 3.9$ mm i.d., $4 \mu \mathrm{m}$ (Waters Nova-Pack, Milford, MA) reverse phase C18 column. All the chromatographic information was reprocessed on a Star Workstation (ver. 4.5) supplied by Varian. Chromatographic conditions were as follows: mobile phase flow rate $1 \mathrm{~mL} / \mathrm{min}$ from 0 to $12.3 \mathrm{~min}, 0.7 \mathrm{~mL} / \mathrm{min}$ for $5 \mathrm{~min}$, and then 1 $\mathrm{mL} / \mathrm{min}$ until stop time; injection volume, $50 \mu \mathrm{L}$; and solvents, A water/acetonitrile/methanol (83:8.5:8.5), and B water/acetonitrile/acetic acid (49.5:49.5:1). The elution program was as follows: 100\% A isocratically for 12 min, $100 \%$ of B in A for $0.3 \mathrm{~min}$, and $100 \%$ B isocratically for $8.7 \mathrm{~min}$. Detection was carried out using a wavelength program with excitation and emission wavelengths of 332 and $478 \mathrm{~nm}$, respectively, for ochratoxin A.

Table 1. Nomenclature of the samples, amounts reacted and positions of the PXRD maxima corresponding to diffraction by planes (003).

\begin{tabular}{cccccc}
\hline Sample & $\mathrm{mmol} \mathrm{Zn}^{2+}$ & $\mathrm{mmol} \mathrm{Al}^{3+}$ & mmol of phenylalanine & $\begin{array}{c}\text { mmol of ac. } \\
\text { isocuomarin }\end{array}$ & $\begin{array}{c}\text { mmol of } \\
\text { OTA }\end{array}$ \\
\hline ZnAlph & 50 & 25 & 50 & & $\begin{array}{c}\text { PXRD } \\
\mathrm{d}_{003}(\AA)\end{array}$ \\
ZnAlc & 50 & 25 & 50 & $1.24 \times 10^{-2}$ & 18 \\
ZnAlOTA & 2.48 & 1.24 & & 16 \\
\hline
\end{tabular}




\section{Results and Discussions}

\subsection{Element Chemical Analyses}

Element chemical analyses data for metals, carbon, nitrogen and hydrogen are included in Table 2. Despite the $\mathrm{Zn} / \mathrm{Al}$ ratio in the starting solutions was 2 in all cases, it decreased in the solids to values amounting $87 \%$, 79\% and $75 \%$ for samples ZnAlc, ZnAlph and ZnAlOTA, respectively, indicating an enrichment of the trivalent cation in the brucite layers. The lack of full agreement between these ratios is rather common in the literature and has been ascribed to a preferential precipitation of one or another cation as a hydroxide during the stirring process [18]. As concluded from other characterisation techniques applied (ee below), samples ZnAlph and ZnOTA contain a contamination by nitrate from the original reagents.

\subsection{Powder X-Ray Diffraction}

The PXRD patterns for samples are shown in Figure 2. All patterns indicate the formation of a well-crystallized hydrotalcite-like phase, although with impurities in some cases, with harmonics due to the basal planes (00l), which confirms a layered structure. Crystallinity is high in ZnAlph and ZnAlc, as concluded from the marked sharpness of the maxima. The patterns for samples ZnAlph and ZnAlc show characteristic (003) reflections corresponding to spacings of 17 and $18 \AA$ (Table 1), respectively, well above the value expected for a nitrate- containing sample with a low $\mathrm{Zn} / \mathrm{Al}$ molar ratio, $8.6 \AA$ [27]. These values are consistent with the formation of swelled structures as a result of intercalation of the rather large organic anions [28]-[30].

The pattern for sample ZnAlph indicates the presence of a phase responsible for maxima at 17 and $8.6 \AA$, which should correspond to diffraction by planes (003) and (006), respectively, of the phenylalanine-intercalated $\mathrm{LDH}$. However, as it can be concluded from the data in Table 2, the molar $\mathrm{C} / \mathrm{N}$ ration for this sample is ca. 6, a value much lower than that corresponding to phenylalanine, 9, suggesting the presence of an additional phase containing nitrogen. As the $\mathrm{Zn}$ and $\mathrm{Al}$ precursors were used as nitrate salts, the presence of an additional, minor

Table 2. Element Composition of the samples synthesized.

\begin{tabular}{ccccccc}
\hline Sample & $\mathrm{Al}^{\mathrm{a}}$ & $\mathrm{Zn}^{\mathrm{a}}$ & $\mathrm{C}^{\mathrm{a}}$ & $\mathrm{H}^{\mathrm{a}}$ & $\mathrm{N}^{\mathrm{a}}$ & $\mathrm{Zn}^{2+} / \mathrm{Al}^{3+\mathrm{b}}$ \\
\hline ZnAlph & 6.06 & 25.08 & 22.89 & 4.17 & 4.59 & 1.58 \\
ZnAlc & 6.20 & 26.24 & 21.38 & 3.59 & 0.22 & 1.75 \\
ZnAlOTA & 7.67 & 27.63 & 2.82 & 2.90 & 5.37 & 1.50 \\
\hline
\end{tabular}

${ }^{\mathrm{a}}$ Mass percentage; ${ }^{\mathrm{b}}$ Molar ratio.

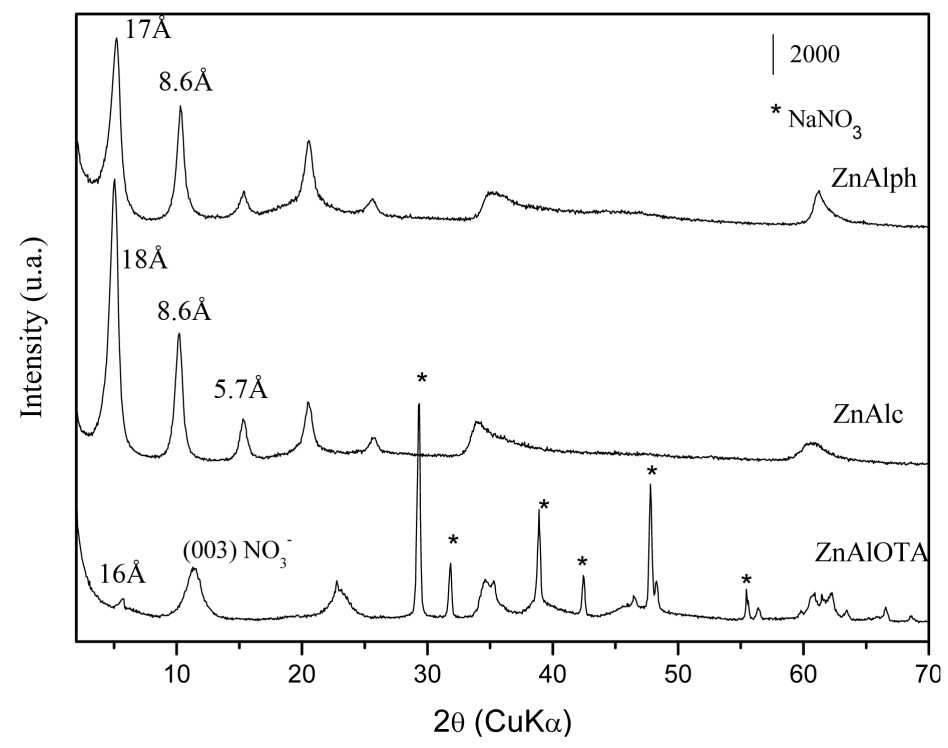

Figure 2. X-ray diffraction patterns. 
phase contaning intercalated nitrate cannot be discarded. This phase would give rise to a maximum, due to diffraction by the (003) planes, close to $8.6 \AA$ and would be obscured by the intense maximum in the same position due to diffraction by planes (006) of the phenylalanine-containing phase. A single maximum is recorded at high $2 \theta\left(60.5^{\circ}\right)$ values, due to diffraction by planes (110) [11] although two maxima are recorded usually in this region, due to diffraction by planes (110) and (113); a single maximum is usually recorded for LDHs containing intercalated organic anions.

These results are similar to those previously reported by Seftel et al. [31] for Mg, Al LDHs (molar ratio 3) intercalated with phenylalanine. Fei-Peng et al. [32] reported a (003) spacing of $16.8 \AA$ for CuZnAl LDHs containing intercalated phenylalanine prepared by reconstruction [33] [34]. Aisawa et al. [35] have reported a slightly larger swelling (18.6 $\AA$ ) for $\mathrm{ZnAl}$ hydotalcite with a $2 / 1$ molar ratio prepared by coprecipitation at $\mathrm{pH}=$ 8. When the $\mathrm{pH}$ was raised to 9 for this same $\mathrm{Zn} / \mathrm{Al}$ molar ratio the recorded value for $\mathrm{d}(003)$ was $18.1 \AA$ [36] [37]. When Zn-Al hydrotalcites were prepared by the calcination-rehydration reaction method the result obtained depends on the $\mathrm{pH}$ values of work; d(003) of $15.8 \AA(\mathrm{pH}=7), 15.8 \AA(\mathrm{pH}=9.5)$ and $8.0 \AA(\mathrm{pH}=10.5)$ were obtained [38]. However, when the layer cations were $\mathrm{Mg}^{2+}$ and $\mathrm{Al}^{3+}$ and the synthesis was performed at $\mathrm{pH}=10$ the main diffraction maxima were observed at 8.6 and $4.3 \AA$ [35] [38].

Assuming a value of $4.8 \AA$ for the width of the brucite-like layer [23], the height of the interlayer space in our sample results 12.2 $\AA$, larger than the length of the phenylalanine molecule. By using Chemlab (Chem. Office Ultra 9.0, 2005), the calculated dimensions for the phenylalanine molecule are $8.8 \times 5.8 \times 3.1 \AA$. The difference between the heigth of the gallery and the maximum dimension of the intercalated entity is ca. $3.4 \AA$. Consequently, instead of a single layer of intercalated phenylalanine molecules, formation of a tilted bilayer of molecules with side-by-side $\pi-\pi$ interactiond between the phenyl groups, has been previosuly proposed [35] [37].

Direct intercalation of isocoumarin by co-precipitation afforded organo-LDHs with an average interlayer separation of $18 \AA$. The PXRD pattern also showed broad maxima which can be assigned to diffraction by planes (006) and (009) at 8.6 and $5.7 \AA$, respectively. A single, well-crystallized, hydrotalcite-like structure was identified in this case. Contamination by nitrate, if any, should be extremely low, as concluded from element chemical analysis data (Table 2). Taking again $9.1 \AA$ for the length of the anion and a value of $4.8 \AA$ for the width of the brucite-like layer, the interlayer distance calculated was $13.2 \AA$. Probably, the organic molecules were intercalated with their carboxylate group towards the hydroxyl layers. Therefore, it is proposed that molecules probably formed an overlaped bilayer in the LDHs gallery.

Finally, Figure 2 also includes the PXRD diagram of the OTA-intercalated sample. As mentioned above, the amount of OTA in the reaction medium was very low, and so intercalation of the molecules was very low too. Actually, the main maxima in the PXRD diagram of this sample correspond to those of a nitrate-LDH phase, and only a minor, very weak diffraction maximum is recorded at $16 \AA$, which might be tentatively assigned to a OTA-LDH phase.

Some diffraction maxima due to $\mathrm{NaNO}_{3}$ formed along the synthesis step were also recorded; this means that it was not removed during washing because less washing cycles were applied in this case to avoid removal of mycotoxin.

According to Lee et al. [39], the dimensions of the OTA molecule are $16.0 \times 5.0 \AA$, while the height of the interlayer space, as calculated from the spacing of the reflection due to planes (003) and the witdh of the brucite-like layers, is $11.8 \AA$, suggesting again a tilted orientation of the bilayer, Figure 3 . When a zeolite Linde type $\mathrm{L}$ is used as sorbent OTA is located within the channels because their dimension the channels are formed by columns of zeolite units diameter of the units is $1.26 \mathrm{~nm}$ and the diameter of the connecting windows 0.71 $\mathrm{nm}$, so large enough to accommodate the OTA molecular, with diameter of $0.5 \mathrm{~nm}$ and a length of $1.60 \mathrm{~nm}$.

\subsection{FT-IR Spectra}

The FT-IR spectra of the solids prepared are included in Figure 4. For all three samples the spectra show typical bands of the layered components, composed of absorption bands due to normal vibration modes of layer hydroxyl groups, water molecules, $\mathrm{M}-\mathrm{O}$ and $\mathrm{M}-\mathrm{O}-\mathrm{M}^{\prime}$ stretching vibrations, which have already been reported in the literature [40] [41].

The FT-IR spectrum of sample ZnAlph shows absorption bands which demonstrate incorporation of phenylalanine within the LDH structure. The amine $\mathrm{N}-\mathrm{H}$ stretching mode is recorded at $2930 \mathrm{~cm}^{-1}$. The C-H stretching 


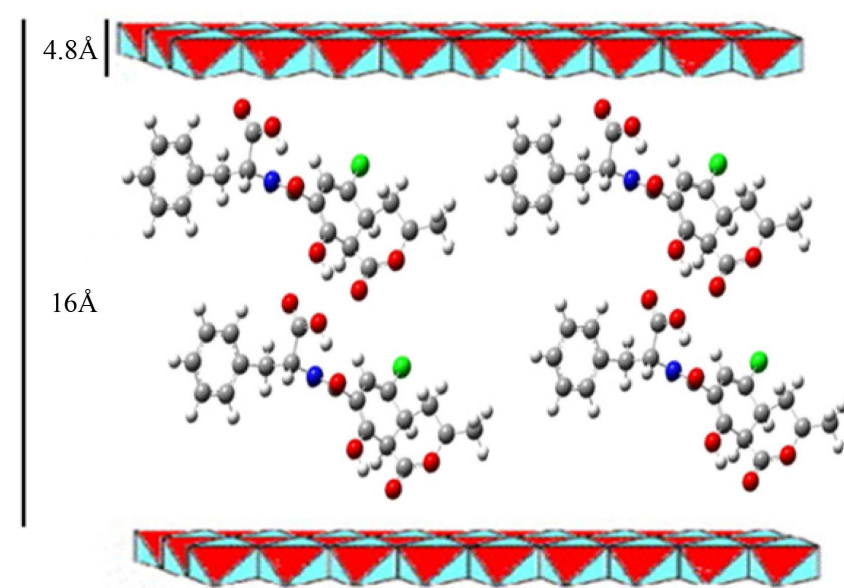

Figure 3. Probable orientation of the OTA between the ZnAl-hydroxide layers.

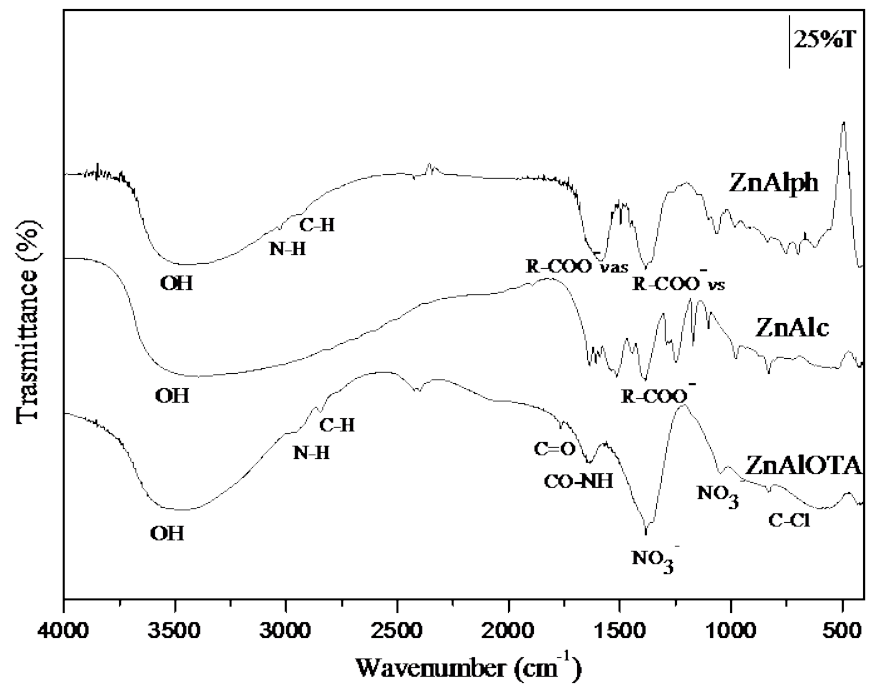

Figure 4. FTIR spectra of the samples.

mode is recorded at $3042 \mathrm{~cm}^{-1}$ [35]. The intense bands recorded at $1580 \mathrm{~cm}^{-1}$ and $1400 \mathrm{~cm}^{-1}$ are assigned to the antisymmetric and symmetric stretching modes, respectively, of the carboxylate group, and the weak absorptions due to mono substituted benzene are recorded in the $770-680 \mathrm{~cm}^{-1}$ range [38]. The presence of nitrate species can be concluded from the peak superimposed to the band of the symmetric stretching mode of the carboxylate group at $1385 \mathrm{~cm}^{-1}$.

No bands due to the presence of nitrate species were recorded in the spectrum of sample ZnAlc, further confirming the purity of this sample, suggested by the element chemical analysis and the PXRD results. The most significant bands are those recorded at 1637 and $1600 \mathrm{~cm}^{-1}$, due to the lactone, although they are shifted with respect to the positions of free lactones with six-member rings [42]. The bands between 1176 and $1000 \mathrm{~cm}^{-1} \mathrm{can}$ be ascribed to the pirane C-O moiety. The stress introduced by the ring in the lactone increases the energy of the carbonyl group stretching mode.

In the spectrum of sample ZnAlOTA the band due to the C-Cl stretching mode is expected at $730-720 \mathrm{~cm}^{-1}$, but it is buried in the stronger bands due to the M-O stretching modes. Two weak bands at 3000 and $2840 \mathrm{~cm}^{-1}$ are due to $\mathrm{N}-\mathrm{H}$ and C-H stretching modes, respectively. A more intense band at $1640 \mathrm{~cm}^{-1}$ is due to the presence of the secondary amide and overlaping of the band due to the carbonyl group. A new weak band at $1760 \mathrm{~cm}^{-1}$, not recorded in the spectra of the previously discussed samples, is due to the $\mathrm{C}=\mathrm{O}$ stretching vibration from the carbonyl and the carboxylic acid groups. A band at $3380 \mathrm{~cm}^{-1}$ is ascribed to the hydroxyl groups, and its position 
coincides within the broad band for the $\mathrm{OH}$ groups of the hydrotalcite structure.

The presence of nitrate is confirmed by the sharp band at $1367 \mathrm{~cm}^{-1}$, due to mode $v_{3}$, and another one at 1066 $\mathrm{cm}^{-1}$, due to mode $v_{1}$, which activity is due to a decrease in the symmetry (originally $\mathrm{D}_{3 \mathrm{~h}}$ ) of the intercalated nitrate anion.

\subsection{Thermal Analyses}

The analysis was performed from room temperature up to $900^{\circ} \mathrm{C}$. The curves are displayed in Figure 5 and Figure 6. At a first sight, all curves are similar to each other, showing three mass losses, although differently defined. The first step corresponding to the removal of adsorbed and interlayer water extends up to $220^{\circ} \mathrm{C}$, and the second step, due to both the dehydroxylation of the LDH basal layer and the decomposition of anion organic is recorded in the $220^{\circ} \mathrm{C}-500^{\circ} \mathrm{C}$ range. The third step corresponds to the combustion of the intercalated organic ions. Total mass losses were 62\%, 54\%, and 42\%, respectively, for samples ZnAlph, ZnAlc, and ZnAlOTA. As the organic anions were burnt off during the analysis, the residues at the maximum temperature reached were a

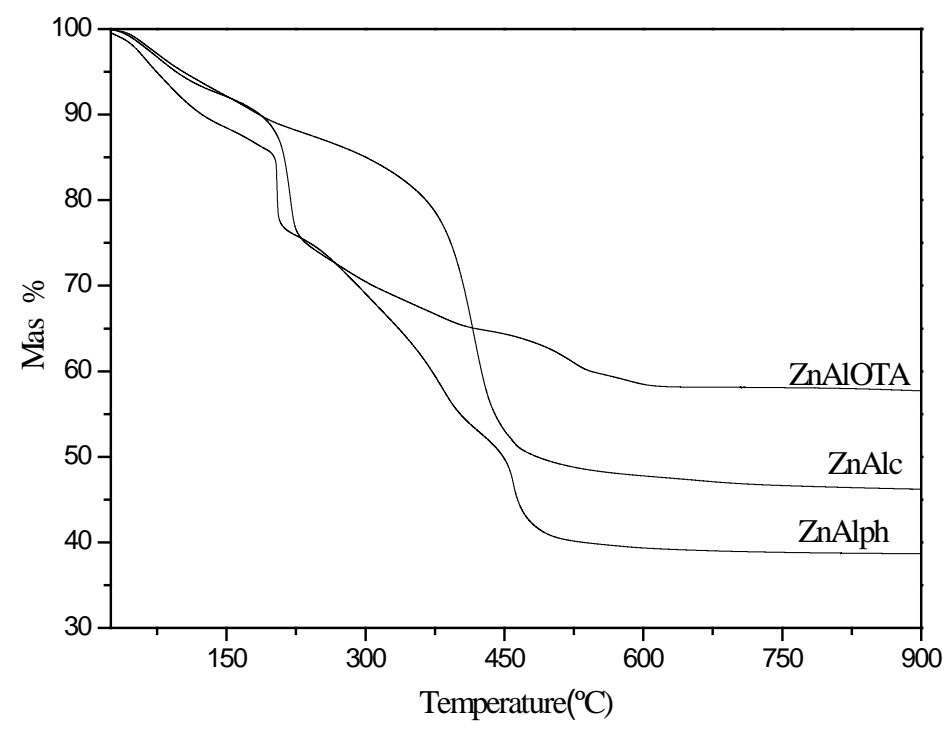

Figure 5. Thermogravimetric analysis curves.

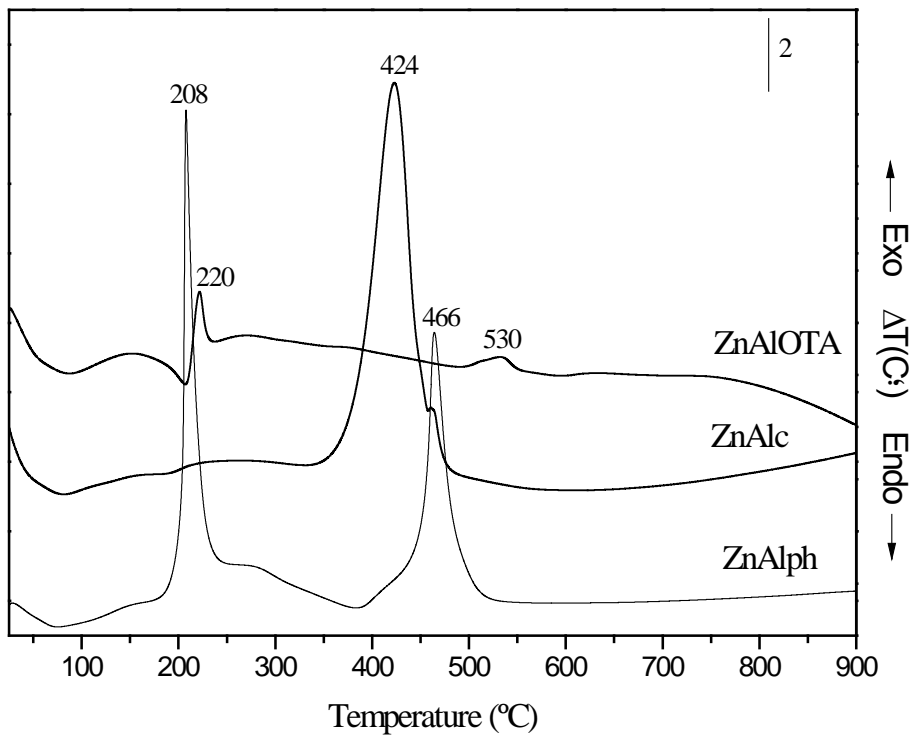

Figure 6. Differential thermal analysis curves. 
mixture of $\mathrm{Zn}$ and $\mathrm{Al}$ oxides.

Differential thermal analysis of sample ZlAlph shows two strong exothermal effects at $208^{\circ} \mathrm{C}$ and $466^{\circ} \mathrm{C}$. The very large intensity of these peaks does not allow a clear identification of the weaker endothermic effect around $100^{\circ} \mathrm{C}$ due to removal of adsorbed water molecules. The DTA trace of phenylalanine only shows three thermal effects, one of them endothermic due to the decomposition, and two exothermic effects at $385^{\circ} \mathrm{C}$ and $528^{\circ} \mathrm{C}$ due to combustion of the organic molecule. When the amino acid was intercalated within the LDH layers combustion also gave rise to two effects, but at temperatures lower than those for pure phenylalanine.

This combustion is carried out in two steps, where the first peak implies the removal of the lateral chain and the second one is associated to the loss of organic mass adhered to the layer in the interlayer space. However, the curve for sample ZnAlc shows a single, strong, exothermic effect at $424^{\circ} \mathrm{C}$, due to combustion of the organic anion.

Finally, the curve for sample ZnAlOTA shows a weak endothermic effect which can be tentatively ascribed to removal of the nitrate anions existing in a large concentration in this sample [27]. This is immediately followed by an exothermic effect at $220^{\circ} \mathrm{C}$, and another exothermic effect is recorded at $530^{\circ} \mathrm{C}$. These are, however, weaker than for the other two samples, probably because of the much lower concentration of organic anion in this sample. The process of combustion of the organic interlayer anions is carried out in two steps as observed for the phenylalanine sample. The first endothermic peak was at $220^{\circ} \mathrm{C}$ and the second peak was the combustion of the organic residue at $530^{\circ} \mathrm{C}$.

\subsection{LC-FD Analysis}

As mentioned above, OTA is a mycotoxin which handling required a strict control, because of its high toxicity. In this study the control of the toxin is extremely important and caution should be taken to handle it very carefully.

In this way very small amounts of OTA result detectable [43]-[45]. OTA retention time was 17 min [44], although this depends on the specific experimental and instrumental conditions used, resulting in values of 11.30 min [46] [47], $12.26 \mathrm{~min}$ [45] or $13.25 \mathrm{~min}$ at low $\mathrm{pH}$ values a [48].

The chromatograms recorded are shown in Figure 7. The chromatogram was first obtained for a sample after $24 \mathrm{~h}$ ageing after addition of the $\mathrm{Zn}$ and $\mathrm{Al}$ cations solution to the OTA solution (Figure 7(a)); the amount of OTA corresponds to the total amount added as the sample has not been centrifuged nor washed.

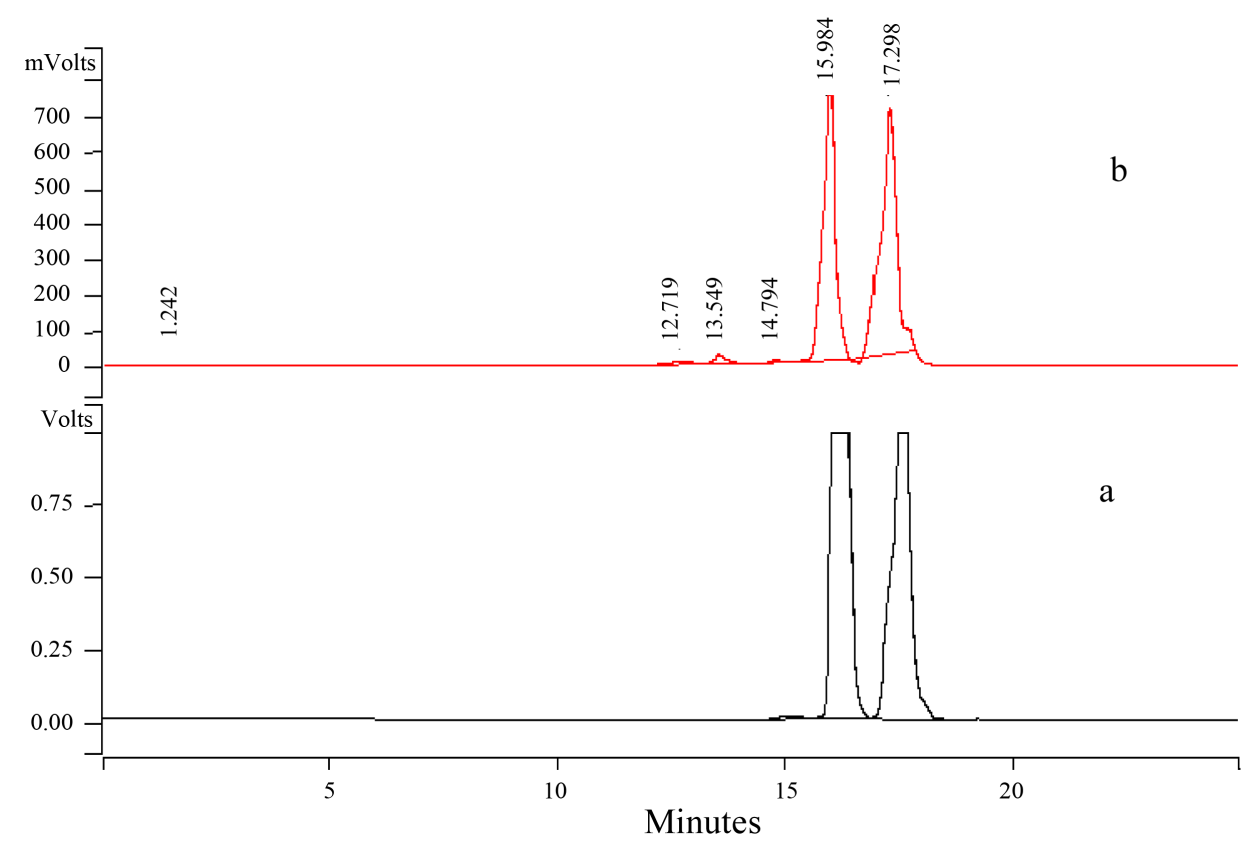

Figure 7. HPLC chromatograms corresponding to ZnAlOTA. (a) Sample after 24 h ageing; (b) Supernatant liquid. 
The amount of OTA is so high that it exceeds the saturation level of the instrument; the peak is recorded at $17.29 \mathrm{~min}$. An additional signal at $15.98 \mathrm{~min}$ is difficult to be assigned, although it might correspond to OTA too, as this is the single detectable species. Probably one signal corresponds to OTA adsorbed on the external surface of the crystallites and the other to OTA from the interlayer. The sample was centrifuged at $3000 \mathrm{rpm}$ after $24 \mathrm{~h}$. However, the supernatant liquid was actually a suspension probably containing LDH microparticles. The chromatogram of the supernatant liquid is shown in Figure 7(b); it shows two peaks at 17.29 and $15.98 \mathrm{~min}$; this last peak is much weaker than that in Figure 7(a), suggesting that OTA has become actually intercalated between the LDH layers. From the integrated areas of these peaks, we may conclude that the amounts of intercalated and externally adsorbed OTA are rather close to each other. One advantage of this technique is that it permit to discriminate between the anions existing inside or outside the layers.

\section{Conclusion}

Well crystallized hydrotalcites with two organic anions which reaction leads to formation of OTA have been prepared and characterized following several physicochemical techniques. A sample containing intercalated OTA has been also prepared, and it is shown that the mycotoxin is partially intercalated and partially adsorbed on the external surface of the crystallites. The results suggest that LDHs may be suitable materials to remove OTA existing as contaminants in several foods, as LDHs are not toxic, are easily prepared and are cheap.

\section{Acknowledgements}

Authors thank financial support from Fundación Caja Rural de Zamora.

\section{References}

[1] Anli, E. and Bayram, M. (2009) Ochratoxin A in Wines. Food Reviews, 25, 214-232. http://dx.doi.org/10.1080/87559120902956182

[2] Alldrick, A.J. (1996) The Effects of Processing on the Occurrence of Ochratoxin A in Cereals Supplement of Volume. Food Additives and Contaminants, 13, 27-28.

[3] International Agency for Research on Cancer, IARC (1993) Monograph on the Evaluation of Carcinogenic Risks to Humans. IARC, Lyon, 489.

[4] International Agency for Research on Cancer, IARC (1983) Ochratoxin A. In Some Food Additives. In: Feed Additives and Naturally Occurring Substances, Lyon, 191-206.

[5] ChemSources (2010) Chem Sources-Chemical Search. Chemical Sources International. http://www.chemsources.com/chemonline.html

[6] Monaci, L., Tantillo, G. and Palmisano, F. (2004) Determination of Ochratoxin A in Portuguese Rice Samples by High Performance Liquid Chromatography with Fluorescence Detection. Analytical and Bioanalytical Chemistry, 378, 1777-1780.

[7] Yu, J.C.C. and Lai, E.P.C. (2010) Molecularly Imprinted Polymers for Ochratoxin A Extraction and Analysis. Toxins, 2, 1536-1553. http://dx.doi.org/10.3390/toxins2061536

[8] Ringot, D., Chango, A., Schneider, Y.J. and Larondelle, Y. (2006) Toxicokinetics and Toxicodynamics of Ochratoxin A, an Update. Chemico-Biological Interaction, 159, 18-46. http://dx.doi.org/10.1016/j.cbi.2005.10.106

[9] Cole, R.J., Jarvis, B.B. and Schweikert, M.A. (2003) Ochratoxins and Related Metabolites. In: Handbook of Secondary Fungal Metabolites, Academic Press, San Diego, 615-624. http://dx.doi.org/10.1016/b978-012179460-6/50368-0

[10] Rives, V. (Ed.) (2001) Layered Double Hydroxides: Present and Future. Nova Sci. Pub, New York.

[11] Cavani, F., Trifiro, F. and Vaccari, A. (1991) Hydrotalcite-Type Anionic Clays: Preparation, Properties and Applications. Catalysis Today, 11, 173-301. http://dx.doi.org/10.1016/0920-5861(91)80068-K

[12] Wang, B., Zhang, H., Evans, D.G. and Duan, X. (2005) Surface Modification of Layered Double Hydroxides and Incorporation of Hydrophobic Organic Compounds. Materials Chemistry and Physics, 92, 190-196. http://dx.doi.org/10.1016/j.matchemphys.2005.01.013

[13] Jaubertie, C., Holgado, M.J., San Román, M.S. and Rives, V. (2006) Structural Characterization and Delamination of Lactate-Intercalated Zn, Al-Layered Double Hydroxides. Chemistry of Materials, 18, 3114-3121. http://dx.doi.org/10.1021/cm060512y

[14] San Román, M.S., Holgado, M.J., Jaubertie, C. and Rives, V. (2008) Synthesis, Characterisation and Delamination Behaviour of Lactate-Intercalated Mg, Al-Hydrotalcite-Like Compounds. Solid State Sciences, 10, 1333-1341. 
http://dx.doi.org/10.1016/j.solidstatesciences.2008.01.026

[15] San Román, M.S., Holgado, M.J., Salinas, B. and Rives, V. (2012) Characterisation of Diclofenac, Ketoprofen or Chloramphenicol Succinate Encapsulated in Layered Double Hydroxides with the Hydrotalcite-Type Structure. Applied Clay Science, 55, 158-163. http://dx.doi.org/10.1016/j.clay.2011.11.010

[16] San Román, M.S., Holgado, M.J., Salinas, B. and Rives, V. (2013) Drug Release from Layered Double Hydroxides and from Their Polylactic Acid (PLA) Nanocomposites. Applied Clay Science, 71, 1-7. http://dx.doi.org/10.1016/j.clay.2012.10.014

[17] Costantino, V.R.L. and Pinnavaia, T.J. (1995) Basic Properties of $\mathrm{Mg}^{2+}{ }_{1-\mathrm{x}} \mathrm{Al}^{3+}{ }_{\mathrm{x}}$ Layered Double Hydroxides Intercalated by Carbonate, Hydroxide, Chloride, and Sulfate Anions. Inorganic Chemistry, 34, 883-892. http://dx.doi.org/10.1021/ic00108a020

[18] Holgado, M.J., Malet, P., Rives, V. and San Román, M.S. (1996) Hexacyanoferrate-Interlayered Hydrotalcite. Solid State Ionics, 92, 273-283. http://dx.doi.org/10.1016/S0167-2738(96)00478-X

[19] Choy, J.H., Choi, S.J., Oh, J.M. and Park, T. (2007) Clay Minerals and Layered Double Hydroxides for Novel Biological Applications. Applied Clay Science, 36, 122-132. http://dx.doi.org/10.1016/j.clay.2006.07.007

[20] Goh, K.H., Lim, T.T. and Dong, Z. (2008) Application of Layered Double Hydroxides for Removal of Oxyanions: A Review. Water Research, 42, 1343-1368. http://dx.doi.org/10.1016/j.watres.2007.10.043

[21] Martínez-Gallegos, S., Herrero, M. and Rives, V. (2008) Preparation of Composites by in Situ Polymerisation of PET-Hydrotalcite Using Dodecylsulphate. Materials Science Forum, 587, 568-571. http://dx.doi.org/10.4028/www.scientific.net/MSF.587-588.568

[22] Rives, V., Carriazo, D. and Martín, C. (2010) Heterogeneous Catalysis by Polyoxometalate-Intercalated Layered Double Hydroxides. In: Gil, A., Korili, S.A., Vicente, M.A. and Trujillano, R., Eds., Pillared Clays and Related Catalysts, Springer, New York, 319-397. http://dx.doi.org/10.1007/978-1-4419-6670-4_12

[23] Miyata, S. (1975) The Syntheses of Hydrotalcite-Like Compounds and Their Structure and Physico-Chemical Properties-I: The Systems $\mathrm{Mg}^{2+}-\mathrm{Al}^{3+}-\mathrm{NO}_{3}^{-}, \mathrm{Mg}^{2+}-\mathrm{Al}^{3+}-\mathrm{Cl}^{-}, \mathrm{Mg}^{2+}-\mathrm{Al}^{3+}-\mathrm{ClO}_{4}^{-}, \mathrm{Ni}^{2+}-\mathrm{Al}^{3+}-\mathrm{Cl}^{-}$and $\mathrm{Zn}^{2+}-\mathrm{Al}^{3+}-\mathrm{Cl}^{-}$. Clays and Clay Minerals, 23, 369-375. http://dx.doi.org/10.1346/CCMN.1975.0230508

[24] The Chemical Database (2010) The Chemical Database. The Department of Chemistry at the University of Akron. Search on CAS Number. http://ull.chemistry.uakron.edu/erd

[25] HSDB (2010) Hazardous Substances Data Bank. National Library of Medicine. http://toxnet.nlm.nih.gov/cgi-bin/sis/htmlgen?HSDB and search on CAS number

[26] JCPDS (1977) Joint Committee on Powder Diffraction Standards, International Centre for Diffraction Data, Pennsylvania, USA.

[27] Arco, M., Gutiérrez, S., Martín, C., Rives, V. and Rocha, J. (2000) Effect of the Mg:Al Ratio on Borate (or Silicate)/ Nitrate Exchange in Hydrotalcite. Journal of Solid State Chemistry, 151, 272-280. http://dx.doi.org/10.1006/jssc.2000.8653

[28] Kameda, T., Takeuchi, H. and Yoshioka, T. (2009) Hybrid Inorganic/Organic Composites of Mg-Al Layered Double Hydroxides Intercalated with Citrate, Malate, and Tartrate Prepared by Co-Precipitation. Materials Research Bulletin, 44, 840-845. http://dx.doi.org/10.1016/j.materresbull.2008.09.003

[29] Perioli, L., Ambrogi, V., Di Nauta, L., Nocchetti, M. and Rossi, C. (2011) Effects of Hydrotalcite-Like Nanostructured Compounds on Biopharmaceutical Properties and Release of BCS Class II Drugs: The Case of Flurbiprofen. Applied Clay Science, 51, 407-413. http://dx.doi.org/10.1016/j.clay.2010.12.019

[30] Miyoshi, T., Yoshii, K., Murayama, N. and Shibata, J. (2013) Modification of Layered Double Hydroxide with Anionic Surfactants and Its Application. Asia Science and Technology Portal, 39, 445-451. http://dx.doi.org/10.1252/kakoronbunshu.39.445

[31] Seftel, E.M., Cool, P. and Lutic, D. (2013) Mg-Al and Zn-Fe Layered Double Hydroxides Used for Organic Species Storage and Controlled Release. Materials Science and Engineering C, 33, 5071-5078. http://dx.doi.org/10.1016/j.msec.2013.08.041

[32] Jiao, F.P., Fu, Z.D., Shuai, L., and Chen, X.Q. (2012) Removal of Phenylalanine from Water with Calcined CuZnAl$\mathrm{CO}_{3}$ Layered Double Hydroxides. Transactions of Nonferrous Metals Society of China, 22, 476-482. http://dx.doi.org/10.1016/S1003-6326(11)61201-6

[33] Chibwe, K. and Jones, W. (1989) Intercalation of Organic of Inorganic Anions into Layered Doluble Hydroxides. Journal of the Chemical Society, Chemical Communications, 926-927. http://dx.doi.org/10.1039/c39890000926

[34] Pinnavaia, T.J., Rameswaran, M., Dimotakis, E.D., Giannelis, E.P. and Rightor, E.G. (1989) Carbon Monoxide Hydrogenation Selectivity of Catalysts Derived from Ruthenium Clusters on Acidic Pillared Clay and Basic Layered Double-Hydroxide Supports. Faraday Discussions of the Chemical Society, 87, 227-237.

http://dx.doi.org/10.1039/dc9898700227 
[35] Aisawa, S., Takahashi, S., Ogasawara, W., Umetsu, Y. and Narita, E. (2001) Direct Intercalation of Amino Acids into Layered Double Hydroxides by Coprecipitation. Journal of Solid State Chemistry, 162, 52-62. http://dx.doi.org/10.1006/jssc.2001.9340

[36] Fudala, A., Palinko, I. and Kiricsi, I. (1999) Amino Acids, Precursors for Cationic and Anionic Intercalation Synthesis and Characterization of Amino Acid Pillared Materials. Journal of Molecular Structure, 482, 33-37. http://dx.doi.org/10.1016/S0022-2860(98)00835-7

[37] Aisawa, S., Sasaki, S., Takahashi, S., Hirahara, H., Nakayama, H. and Narita, E. (2006) Intercalation of Amino Acids and Oligopeptides into Zn-Al Layered Double Hydroxide by Coprecipitation Reaction. Journal of Physics and Chemistry of Solids, 67, 920-925. http://dx.doi.org/10.1016/j.jpcs.2006.01.004

[38] Aisawa, S., Kudo, H., Hoshi, T., Takahashi, S., Hirahara, H., Umetsu,Y. and Narita, E. (2004) Intercalation Behavior of Amino Acids into Zn-Al-Layered Double Hydroxide by Calcination-Rehydration Reaction. Solid State Chemistry, 177, 3987-3994. http://dx.doi.org/10.1016/j.jssc.2004.07.024

[39] Lee, T.P., Saada, B., Nga, E.P. and Sallehb, B. (2012) Zeolite Linde Type L as Micro-Solid Phase Extraction Sorbent for the High Performance Liquid Chromatography Determination of Ochratoxin A in Coffee and Cereal. Journal of Chromatography A, 1237, 46-54. http://dx.doi.org/10.1016/j.chroma.2012.03.031

[40] Kloprogge, J.T. and Frost, R.L. (2001) Infrared and Raman Spectroscopic Studies of Layered Double Hydroxides (LDHs). In: Rives, V., Ed., Layered Double Hydroxides: Present and Future, Chapter 5, Nova Science Publishers, Inc., New York, 139-192.

[41] Kloprogge, J.T. (2005) Infrared and Raman Spectroscopy of Naturally Occurring Hydrotalcites and Their Synthetic Equivalent. In: Kloprogge, J.T., Ed., The Application of Vibrational Spectroscopy to Clay Minerals and Layered Double Hydroxides, CMS Workshop Lectures, The Clay Mineral Society, Aurora, Vol. 13, 203-238.

[42] Bellamy, L.J. (1980) The Infrared Spectra of Complex Molecules. Chapman and Hall, London. http://dx.doi.org/10.1007/978-94-011-6520-4

[43] Almala, L., Rabe, V., Sánchez, B., Torrella, F., López-Pérez, J.P., Gabaldón, J.A. and Guardiola, L. (2007) Ochratoxin A in Red Paprika: Relation-Ship with the Origin of the Raw Material. Food Microbiology, 24, 319-327. http://dx.doi.org/10.1016/j.fm.2006.08.001

[44] Hernández, J.M., García-Vilanova, R.J., Rodríguez, P. and Toruño, I.M. (2008) Aflatoxins and Ochratoxin A in Red Paprika for Retail Sale in Spain: Occurrence and Evaluation of a Simultaneous Analytical Method. Journal of Agricultural and Food Chemistry, 56, 751-756. http://dx.doi.org/10.1021/jf073002c

[45] Juan, C., Pena, A., Lino, C., Moltó, J.C. and Mañes, J. (2008) Levels of Ochratoxin A in Wheat and Maize Bread from the Central Zone of Portugal. International Journal of Food Microbiology, 127, 284-289. http://dx.doi.org/10.1016/j.ijfoodmicro.2008.07.018

[46] Bento, J.M.V., Pena, A., Lino, C.M. and Pereira, J.A. (2009) Determination of Ochratoxin A Content in Wheat Bread Samples Collected from the Algarve and Bragança Regions, Portugal: Winter 2007. Microchemical Journal, 91, 165-169. http://dx.doi.org/10.1016/j.microc.2008.10.004

[47] Duarte, S., Bento, J., Pena, A., Lino, C.M., Delerue-Matos, C., Oliva-Teles, T., Morais, S., Correia, M., Oliveira, M.B.P.P., Alves, M.R. and Pereira, J.A. (2010) Monitoring of Ochratoxin A Exposure of the Portuguese Population through a Nationwide Urine Survey-Winter 2007. Science of the Total Environment, 408, 1195-1198. http://dx.doi.org/10.1016/j.scitotenv.2009.11.048

[48] Pena, A., Cerejo, F., Silva, L.J.G. and Lino, C.M. (2010) Ochratoxin A Survey in Portuguese Wine by LC-FD with Direct Injection. Talanta, 82, 1556-1561. http://dx.doi.org/10.1016/j.talanta.2010.07.041 